\title{
Asset-Based, Sustainable Local Economic Development: Using Community Participation to Improve Quality of Life Across Rural, Small-Town, and Urban Communities
}

Matt Kammer-Kerwick ( $\nabla$ mattkk@ic2.utexas.edu )

The University of Texas at Austin https://orcid.org/0000-0001-8848-3438

Kara Takasaki

The University of Texas at Austin https://orcid.org/0000-0002-7278-1622

\section{J. Bruce Kellison}

The University of Texas at Austin

Jeff Sternberg

The University of Texas at Austin https://orcid.org/0000-0002-7907-1367

\section{Research Article}

Keywords: Sustainable Community Development, Community Participatory Research, Assets, Values, Identity, Quality of Life

Posted Date: December 3rd, 2021

DOI: https://doi.org/10.21203/rs.3.rs-1138803/v1

License: @ (i) This work is licensed under a Creative Commons Attribution 4.0 International License. Read Full License 


\section{Abstract}

We analyze survey data from 5,487 residents of 85 Texas communities, including rural communities, small towns, mediumsized cities, and the five largest urban centers, to model the influence of the degree of urbanity and rurality of a community as well as residents' social position, values, and their satisfaction with local assets. The paper's central argument is that a wide range of factors impact how community members think about their needs and thus should be considered in any community development process. This human-centered approach to looking at how these factors impact economic and quality-of-life development project preferences will support the adaptation of community development decision-making processes to the conditions of each community. For the sake of parsimony, the present study presents results for three community development project concepts: 1) renovating some downtown buildings as mixed-use facilities with retail shops and apartments, 2) opening a community health center, and 3) and deploying gigabit high-speed fiber broadband internet in the downtown area. Our findings specifically highlight areas where participatory processes can be introduced to guide further interactions between experts and community members to 1) identify groups in the community to bring into the process who may be most impacted by the choice of one intervention over another, and 2) target areas where further community discussion and deliberation is necessary around which community dialogues (round tables, town halls, workshops, etc.) could be facilitated.

\section{Introduction}

People who want to improve quality of life in the place where they live must often make choices constrained by other residents' preferences and priorities about which projects have the best fit for their shared community. With fewer resources, smaller, more rural communities often have less room for error. Moreover, the migration of more educated workers and prime working-age residents from rural to urban areas puts economic stress on rural communities (Domina 2006; Kilkenny 2010; Parker et al. 2018).

Researchers have studied social, cultural, and political divisions between urban and rural residents who are thought to have fundamentally different types of personalities, values, cultures, politics, and needs (Brown \& Kandel 2006; Gimpel et al. 2020; Kellogg Foundation 2002; ). These differences in the social, cultural, and political characteristics of urban and rural America have been chalked up to the relative isolation of rural communities from the social and cultural influences of the city, seen as a preserve of traditional American values (Logan 1996), or a stagnant cultural backwater of reactionary conservativism and underdevelopment ( Lewis 1998). Each type of settlement is thought to either produce or reinforce different personality types, whose interaction in these spaces produces sets of values and cultural frameworks that evaluate the world differently, which in turn make different types of decision-making, actions, and outcomes possible over others.

Yet, studying quality of life through an urban-rural binary is a simplification of the way that regional contexts develop. Schema for classifying a community as urban or rural abound and change over time (for a review see National Academies of Sciences and Medicine, 2016, Appendix B). Communities can be more accurately seen as possessing a degree of urbanity and rurality by incorporating multiple dimensions of information that include local population size, local population density, and commuting distance to sources of employment, healthcare, culture, and other forms of entertainment.

We examined these issues formally by addressing the following research questions:

1. How, if at all, do community size, population density, and distance to a major metropolitan area predict preferences for and priorities among various community development project concepts?

2. How do community members' social position (for instance, age, race, income) predict preferences for community development project concepts? 
3. To what degree do personality types and personal values help predict preferences for community development project concepts?

4. To what degree does community satisfaction with and the perceived importance of assets available in a community further improve predictions about preferences for various community development project concepts?

To answer these research questions, we present the findings of a survey fielded in the summer and fall 2020 (during COVID-19) of Texas residents that asked participants to allocate hypothetical "points" toward 6 distinct economic development project concepts for their town (for a rural resident) or neighborhood (for a big-city resident). We analyze survey data from 5,487 residents of 85 Texas communities, including rural communities, small towns, medium-sized cities, and the five largest urban centers to predict respondent economic and quality-of-life priorities based on a community's degree of urbanity and rurality and individual respondents' social position, community values, personality types, and community asset satisfaction and importance. The paper's central argument is that a wide range of factors impact how community members think about their needs and thus should be considered in any community development process. This human-centered approach to looking at how these factors impact economic and quality-of-life development project preferences will support the adaptation of community development decision-making processes to the conditions of each community.

\section{The Role of Community and Quality of Life in Economic Development}

Economic development theories and practice commonly address sustainability across multiple objectives and decisionmaking criteria,. Sustainable Local Economic Development (SLED) is a model that incorporates the community into the development process with a focus on producing equitable long-term solutions (Newby, 1999). SLED's concern with sustainability comes from its critique of traditional economic development practices, which viewed development, and the assets and values that it is based on, from the narrow view of economic actors (external capital and local elites) operating outside of any given community. Traditional development approaches were performed by elites and technicians who viewed a community as a source of labor, infrastructure, and raw materials for supporting a given type of economic or business activity. In the traditional model, communities that wanted economic development presented themselves through the previous lens to attract outside capital because any economic activity or growth placed in a community was believed to be a net good (Vaughan, Pollard \& Dyer 1984).

SLED starts from the basis that economic activity and growth may not be good for its own sake; economic development must also concern itself with how economic activity impacts the lives of the communities incorporated into it. SLED holds that the needs of community members should be considered in the economic development decision-making process. The community needs should be used to guide selection over which type of development intervention should be chosen based on equitably balancing trade-offs between outside capital and the community, asking whether an intervention or project improves the future quality of life, equity, participation, and partnership in the community, even if privileged or institutional economic actors were to end their involvement.

Asset-Based Community Development (ABCD) moved beyond SLED to frame a community not just as a partner to economic development but as a system of subsystems, the economy being one of many subsystems, that needs to be developed to maintain a balance or equilibrium (Nel 2018). ABCD addresses these subsystems broadly, including rights, capacities, and capabilities across human, physical, financial, natural, political, social, spiritual, and cultural assets (or capitals). ABCD is guided by the principles that everyone has gifts, relationships build a community, leaders involve others as active members of the community, people care about something, and that people can be motivated to act. These principles and the ABCD approach operate to mobilize 5 key assets: individuals, associations, institutions, physical assets, and connections (Collaborative for Neighborhood Transformation 2020). From this basis, Asset-Based Community Development starts at the level of the individual, who is thought to have their own talents and assets to mobilize. The mobilization of these assets toward meeting shared community needs relies first on the individual identifying and 
evaluating their own assets and needs, and from there those of their community. The individual then finds motivation to mobilize these assets and forms connections with other motivated community members to create associations and wield institutions to connect different communities to meet shared needs.

A focus on the quality of life of the community is a way to plan for sustainable and locally appropriate economic development that requires individual-, community-, and economy-level information. Quality of life serves as a domain of observation from which the balance between economic and community concerns can be measured. Individual needs have been shown to be shaped and impacted by individual personality type and personal values, their individual well-being, and levels of perceived community attachment and community satisfaction (Fried 1982, Theodori 2009). Community-level needs have been shown to be shaped by individual-level needs, and all the factors that are associated with them, as well as by the underlying assets of a given community, levels of community satisfaction with these assets, and the shared culture and values held by individuals coming together as a community (Fried 1984, Hanscott 2016, Garretsen et al. 2019, Stinner and Van Loon 1992). As McGregor, Camfield and Woodcock (2009) find, people identify their needs and interpret their quality of life through a local context, which suggests that economic development should not only assess satisfaction with a community asset but also the importance of that community asset to its community members.

\section{Rural and Urban Community Personality, Values, Satisfaction, and Decision-Making}

Settlement type was the starting point for American Urban Sociology (Park, Burgess, McKenzie 1926) which built from competition and succession models from studies of natural ecology to understand how human behavior is shaped by social structures and factors of the physical environment. This school of thought argued that the ecological pattern of a community - the spatial distribution of its economic, cultural, and social relationships within and among groups - has independent effects on social life separate from those of other explanatory variables. Georg Simmel (1950) was among the first to theorize the impact of settlement type on personality. Simmel argued that rural and urban settings established different conditions for the creation and flourishing of distinct personality types. Rural settings were thought to provide relatively stable, predictable, and habitual ways of life and interaction, with residents not often experiencing change or new kinds of stimuli. When new stimuli were encountered, it would be jarring and reacted to rashly, causing this rural personality type to want to avoid change. This type of personality can be seen to correspond with values of conservativism and tradition. In urban settings, new stimuli were encountered constantly, due to the city's population size, density, and heterogeneity (Wirth 1938), producing high levels of mental energy and stimulation. This type of personality characteristic of urban settings is thought to adopt a jaded and dispassionate stance toward their condition of ever-present instability, tolerating and embracing change as a constant in life, leading to values of openness and progressivism.

Through personality type, urbanity and rurality have been shown to have an impact on community satisfaction, as a product of whether the personality of an individual matches those of the people around them, and whether the location they are in, both in terms of the compilation of personalities clustered within it, and the contours of the community itself, allows that personality to thrive (Fried 1984). It has been shown that cities have different compositions of personality types, which lend themselves to more or less of an entrepreneurial culture, which in turn impacts their economic performance and growth (Garretsen et al 2019). The physical, social, and cultural assets of a community, and its level of social inequality relative to other communities, have also been shown to have a direct and primary effect on levels of residential and community satisfaction (Fried 1982). The types of assets available in a community and their quality are thought to vary across the urban-rural divide, with small rural communities believed to have more responsive local governments, greater social solidarity, and more pleasing physical environments. In contrast, larger cities are thought to have greater economic opportunities, cultural environments, and more highly developed public service infrastructure (Wilkening 1982; Stinner \& Van Loon 1992).

Community satisfaction has been shown to have an impact on decision-making in both urban and rural circumstances and has also been used to evaluate the success or failure of different planning initiatives. One study showed that community 
satisfaction with various community assets and community size preferences are strong predictors of decision-making when it comes to migration intention, this decision-making also influenced by metropolitan versus non-metropolitan residence and whether the migration intention was short-term or long-term (Stinner \& Van Loon 1992). The influence of planning interventions on growth rates and community satisfaction across the urban-rural continuum has also been studied, with Baldassare et al (1982) finding that places that adopted growth controls had lower community satisfaction; however, the impact of community satisfaction on the selection of planning interventions and their outcomes has yet to be studied.

Degree of urbanity and rurality can cause variation in factors (personality type and values, community satisfaction) connected to decision-making processes in general, and community development in particular; however, the relevance and primacy of the interaction effect of settlement type on these factors, and decision-making as a whole, remains an open question. Lichter \& Brown (2011) argue that perceptions about urban and rural communities do not reflect the reality on the ground, with many scholars (Hamilton 2006, Weber et al. 2005) claiming that differences along the urban-rural continuum may have less to do with settlement type than with spatial differences between urban and rural residents such as social boundaries within spatial groups (race, class, gender, etc.). The following analysis will test whether settlement type has an independent effect on decision-making when it comes to community development preferences.

\section{Method}

We compare Texas resident responses in mixed multi-level logistic regression models to explain outcomes of a community investment allocation exercise across economic development and quality-of-life development concepts. We include community size, community population density, and distance of the community from the nearest major urban center to assess the influence of the degree of urbanity and rurality. We include basic human values as well as the personality traits of agreeableness and openness to assess the influence of underlying psychological traits of members of communities. And, we include community members' satisfaction with and the perceived importance of community resources to assess the influence how community members think about resources that are available to them. As controls, we also analyze the effects of demographic variables and perception of emergent COVID-19 impacts on the resident's community. We hypothesize that respondents' values and level of agreeableness would predict-given the constraint of finite resourcespreferences for economic and quality of life interventions. We thought choosing and allocating resources to interventions would be further explained by the degree of satisfaction with what is currently available as well as how important those resources to the community.

\section{Measures}

\section{Schwartz Value Theory}

Schwartz' theory of basic human values (Schwartz, 2012) argues that all cultures are structured by a set of ten distinct personal values. People use values to motivate action toward goals. These goals help people to deal with the universal requirements of being humans who live with other humans. The ten values consist of self-direction, stimulation, hedonism, achievement, power, security, conformity, tradition, benevolence, and universalism. These values form a circular motivational continuum that reflects the conflict and compatibility among values.

Schwartz theory argues that the continuum is organized along two bipolar dimensions, where "openness to change" and "conservation" are compared in one dimension, and "self-enhancement" and "self-transcendence" are compared in another. For example, pursuing the value of self-direction-autonomous control over one's life-in the dimension of openness to change, would conflict with pursuing the value of conformity-group harmony-in the dimension of conservation. Another example would be pursuing a value that upholds the interests of others in the dimension of self-transcendence, like universalism, conflicting with pursuing the value of power, which values dominance over others, in the self enhancement dimension. 
To model the impact of personal values across these bipolar dimensions on community decision-making preferences, we have incorporated resultant self-transcendence (self-transcendence - self enhancement) and resultant conservation (conservation - openness to change) into our survey. This approach is common and has been used in a variety of marketing and business strategy settings (Ahmad, Kim, Anwer, and Zhuang, 2020; Ashraf, Hou, Kim, Ahmad et al., 2020; Keh and Sun, 2008; Steenkamp, ter Hofstede and Wedel, 1999).

\section{Big Five Personality Traits}

The Big Five Inventory (BFI) measures five personality dimensions that are theorized to be and have been tested to be relatively stable and distinct over the life course and applicable across cultures (Cobb-Clark \& Schurer, 2011; Schmitt et al., 2007; Soldz and Vaillant, 1999). These personality dimensions are measured in a way that precludes the need to break down these personality dimensions into lower order measures (John et al., 1991). We measured agreeableness and openness because the research suggested that these personality dimensions would predict a respondent's likelihood to invest in a community intervention. For reasons of parsimony and to avoid survey participant fatigue, we did not include conscientiousness, extraversion, and neuroticism from the BFI.

Agreeableness. From the Big Five Inventory $(\mathrm{BFI})$ we hypothesize that variation in agreeableness would be the personality factor that would best predict whether community members would cooperate toward an intervention. Agreeableness is correlated with wanting to engage in positive actions for society. Agreeableness is positively related to the orientation of Self-Transcendence and to the individual value of Benevolence from Schwartz' value theory.

Openness. Openness to experience is a personality trait whose distinct facets can be broken down into three higher-order measures of intellectual curiosity, active experiencing of senses and emotions, and open mindedness toward different cultural ideas and values (Christensen et al., 2019). Central aspects of openness distinct from other personality traits include willingness to entertain novel ideas and unconventional values, intellectual curiosity and reflection about the inner and outer world, and independent judgement. Openness to experience has been studied in relation to creativity and innovation in social entrepreneurship (Nga and Shamuganathan, 2010), adjustment to change, identification and maintenance of specific communities (Chang et al., 2013; Füller et al., 2008), and engagement with community development interventions (Litchfield and Javernick-Will, 2015). Based on this research, openness to experience seemed to be a personality trait that might predict respondent likelihood to invest in community development interventions.

\section{Asset Satisfaction and Importance}

We asked survey respondents to rate how satisfied they were with eighteen assets of their community, on a scale from $1=$ not at all satisfied to 7 = extremely satisfied. Participants were also asked to assess the importance of these same eighteen assets if they were to be considering relocating to another community $(1=$ not at all important to $7=$ extremely important). The eighteen community assets consist of the following items: broadband internet, cellular or mobile telephone options, arts and culture options, nature and outdoor options, walking and biking options, public transportation, infrastructure conditions, institutions of higher education, K-12 education, housing affordability, housing availability, employment options, cost of living, incentives to start or expand a business, library, healthcare, childcare options, and safe environment.

We expected and confirmed multicollinearity among the community assets. We used exploratory factor analysis (EFA) and reliability analysis to create four mean asset satisfaction subscales from the original eighteen survey items, previously listed, see Table 3. Principal components analysis with varimax rotation $(\mathrm{KMO}=0.916$, sig. $<0.001)$ produced asset themes for broad-based community services, economic environment, family-oriented community services, and communications services with $40.8 \%, 9.2 \%, 6.8 \%$, and $6.0 \%$ variance explained for each, respectively. Average asset scores were defined for this grouping of four asset themes, with reliability analysis adequate for all subscales, Chronbach $a>$ 
0.75. Reliability was not improved by dropping any asset from the subscale characterized by the EFA. We used these same four themes to calculate asset importance subscales.

Table 3. Community Asset Satisfaction Subscales

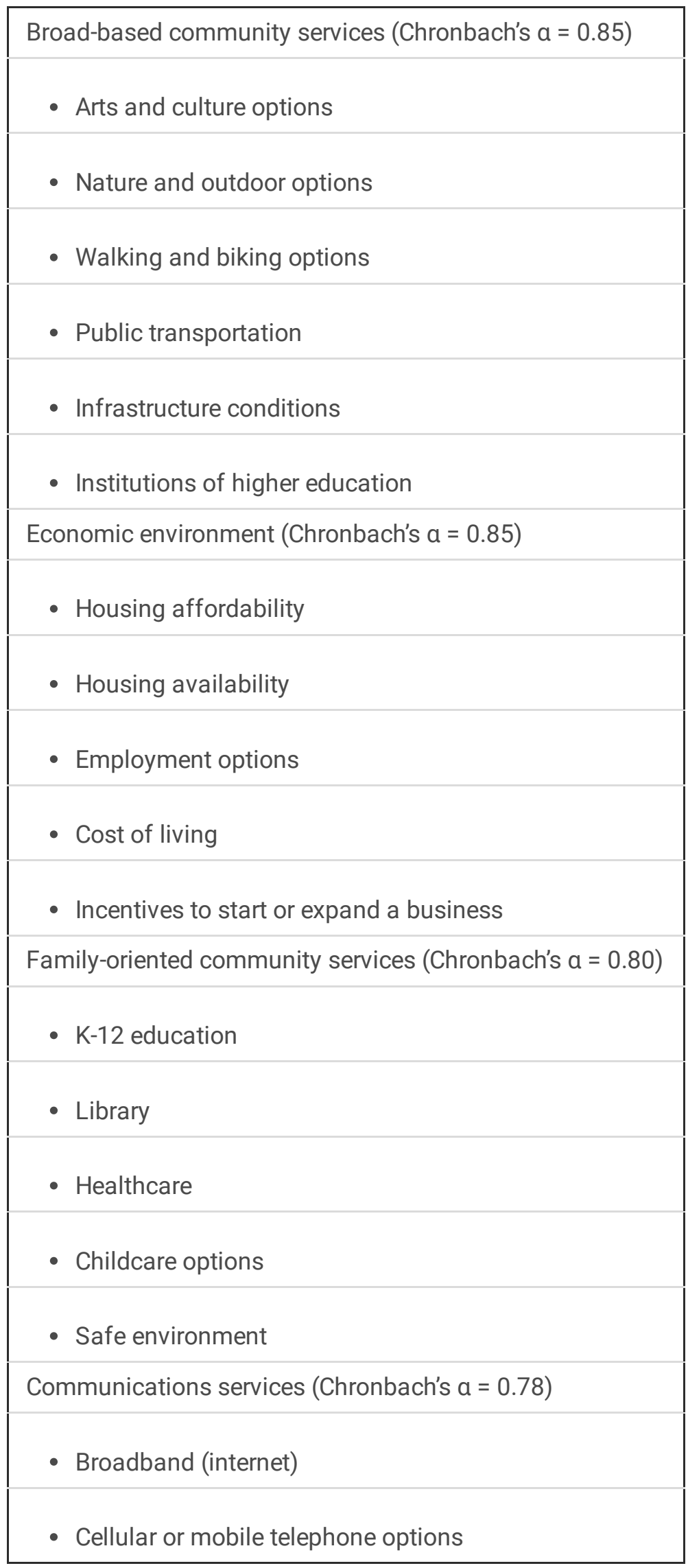


We include other variables that may explain partial variance in intervention interest. These variables include community size, population density of each community, and the distance of each community to the nearest major metropolitan center in Texas. We also include community as a random effect in our analysis because of our multi-site data collection design. We include the age, race, gender, education, and income of community members in sample to assess the role of social position. Lastly, this study was conducted during the COVID-19 pandemic, so we include variables indicating participants' perception of how COVID-19 impacted their community's health and economy.

\section{Interventions}

In a point-allocation exercise, we examined how community members prioritize and make trade-offs among a set of community development project concepts. The concepts chosen for this manipulation are all popular options both considered by and implemented in various community settings (see, for example, Hightree, et al, 2018). We employed very simple descriptions of these community development concepts in this survey, but the concepts were selected based on need expressed in literature as well as from comments obtained during qualitative exercises conducted during the planning phase for this survey.

The allocation exercise asked the participant to "allocate 100 points across the following projects based on how well you think they would fit the needs of (insert resident's community). Allocate more points to projects that you think are a better fit for (insert resident's community). If a project does not have any fit, allocate 0 points to it. If only one project fits (insert resident's community)'s needs, allocate all 100 points to that project." The seven intervention options included the following: Renovating downtown buildings with retail shops and apartments, opening a community health center, deploying high speed internet downtown, adding more computers and meeting spaces in the public library, early college credit and vocational programs for high school students, opening a co-working and startup working space for entrepreneurs, and an "other" category to capture additional significant intervention options. The wording included the phrase "in my neighborhood" for surveys conducted in the 5 major metro areas to localize the context. For example, the first option was worded "renovating some buildings in my neighborhood as mixed-use facilities with retail shops and apartments."

For the sake of parsimony, the present study presents results for three community development project concepts. The results for all seven concepts are available from the corresponding author. We selected renovating some downtown buildings as mixed-use facilities, opening a community health center, and deploying gigabit high-speed fiber broadband internet downtown as the concepts to focus on in this paper because of their relevance in general in our literature review and to the communities included in our study, as will be discussed further in our findings. The motivational context for the chosen concepts is discussed next.

Renovating some downtown buildings as mixed-use facilities. We have observed downtown renovation efforts in small towns in New Hampshire; Lufkin, TX; Sweetwater, TX and Del Rio TX, among others. The benefits of a town center even extend to urban neighborhoods. Specifically, Pendola \& Gen (2008) demonstrated that urban neighborhoods with a "main street" are endowed with a higher sense of community than other urban and suburban neighborhood settings. Gibson, Zurcher, \& Wisemiller (2020) show that direct public-private investment in downtowns of smaller towns has a spillover effect on additional private investment in renovations and maintenance in the downtown area. Powe (2020) compares strategies that have been used successfully by communities, recommending that town centers be thought of as "complex adaptive places, their multi-functionality must be treasured and recognition given to the unpredictability/serendipity of opportunities emerging within them." By renovating downtown to include mixed-use buildings there is an opportunity to increase walkability of the area and increase social capital between residents, thereby also increasing their quality of life (Rogers et al. 2011). This intervention is also important to assess in our gradient of urbanity and rurality because Jeffres 
et al. (2009) found that when people believe they can access "third places", defined as places where people can meet and talk outside of home and work, they perceive a higher quality of life in their community.

Opening a community health center. Community health centers (CHCs) were launched in 1965 during President Lyndon B. Johnson's War on Poverty. CHCs were designed to reduce health disparities experienced by racial and ethnic minorities, the uninsured, and the poor. They provide primary medical, dental, behavioral, and social services to medically underserved populations in medically underserved areas, including migrant and homeless populations that do not have the ability to pay. CHCs have received substantial bipartisan legislative funding to address a growing need for primary care (Adashi et al., 2010). Their presence in a county has been shown to lower the rate of hospitalization for ambulatory care sensitive conditions among older adults and in some cases, for working-age adults as well (Probst et al., 2009). CHCs are models of community oriented primary care and especially serve populations facing language and culture barriers that may need additional translation, interpretation, and transportation services. CHCs are an opportunity for community development by leveraging local resources among critical access hospitals, rural health clinics, and educational institutions (Geiger, 2002; Samuels et al., 2008).

Deploying gigabit high-speed fiber broadband internet downtown. The disparities in access to high-speed internet between urban and rural communities are widely discussed in the media (e.g., CNN's "America's surprising breeding ground for inequality: The internet," May 17, 2020) and by researchers (e.g., Pew Research Center's Internet/Broadband Fact Sheet). These disparities are also central to the Biden Administration's The American Jobs Plan (The White House, 2021) wherein high-speed broadband is considered a fundamental infrastructure along with roads, drinking water, and electricity. Indeed, we have observed Smithville, a small community in Texas, deploy fiber along its main street as a central part of an economic development program intended to attract new business to its community. Other communities have done the same, including Tullahoma, TN; Mount Washington, MA; and Wilson, NC, just to name a few (Hanna \& Mitchell, 2020).

\section{Procedure and Participants}

Data for this paper were collected in two phases, both of which occurred in 2020 during the COVID-19 pandemic. A purposeful community sampling methodology was used to collect data from 80 rural and small-town communities outside of the 5 largest metro areas in Texas (consisting of Dallas/Fort Worth, Houston, Austin, San Antonio, and El Paso). Student researchers promoted the project and distributed links to the web-based survey in rural and small-town communities using a variety of techniques, including social media; telephone calls to local community members and leaders; and distributing electronic fliers to local groups to post on their websites. These communities were incentivized with funding for school computer equipment to be donated to the community with the highest number of completed surveys per capita. Participants from the 5 largest metro areas in Texas were recruited through a commercial panel, Dynata.[1] The rural and small-town surveys were collected during the summer of 2020 while the major metro surveys were collected during the fall of 2020. The study was reviewed and approved by authors' institutional review board.

We analyze survey data from 3,363 residents of the rural and small-town communities and 2,124 residents from the five largest metro areas in Texas. Table 1 summarizes demographic descriptive statistics for the sample. Rural and smalltown communities ranged in population size from Bandera (pop. 910 in 2021) to Amarillo (pop. 199,747 in 2021) with an average of 24,692 and a median of 7325 . The complete list of rural communities is available in the data supplement for this manuscript. The 2021 El Paso metro area population is 963,000. The other 4 metro (Dallas/Fort Worth, Houston, Austin, and San Antonio) areas each have 2021 populations well above 1 million.

Table 1. Sample Demographics 


\begin{tabular}{|c|c|c|}
\hline \multirow[t]{2}{*}{ Gender $(n=5487)$} & Male & $33.0 \%$ \\
\hline & Female & $67.0 \%$ \\
\hline \multirow[t]{7}{*}{ Race/Ethnicity ( $n=5487)$} & White, not Hispanic or Latino & $56.8 \%$ \\
\hline & Hispanic or Latino & $24.2 \%$ \\
\hline & Black or African American & $8.7 \%$ \\
\hline & American Indian or Alaskan Native & $1.0 \%$ \\
\hline & Asian & $5.5 \%$ \\
\hline & Native Hawaiian or Pacific Islander & $0.3 \%$ \\
\hline & Two or more races & $3.6 \%$ \\
\hline \multirow[t]{7}{*}{ Education ( $n=5487)$} & Less than 9th grade & $0.4 \%$ \\
\hline & 9th to 12 th grade, without diploma & $1.6 \%$ \\
\hline & High school diploma or GED & $12.6 \%$ \\
\hline & Some college & $21.7 \%$ \\
\hline & Associate degree & $10.5 \%$ \\
\hline & Bachelor's degree & $30.1 \%$ \\
\hline & Graduate or professional degree & $23.1 \%$ \\
\hline \multirow[t]{7}{*}{ Age $(n=5487)$} & $18-24$ & $10.3 \%$ \\
\hline & $25-34$ & $17.3 \%$ \\
\hline & $35-44$ & $22.8 \%$ \\
\hline & $45-54$ & $19.5 \%$ \\
\hline & $55-64$ & $16.5 \%$ \\
\hline & $65-74$ & $10.8 \%$ \\
\hline & 75 or older & $2.8 \%$ \\
\hline \multirow[t]{10}{*}{ Household income $(n=5439)$} & Less than $\$ 10,000$ & $4.8 \%$ \\
\hline & $\$ 10,000$ to $\$ 14,999$ & $3.4 \%$ \\
\hline & $\$ 15,000$ to $\$ 24,999$ & $5.9 \%$ \\
\hline & $\$ 25,000$ to $\$ 34,999$ & $8.4 \%$ \\
\hline & $\$ 35,000$ to $\$ 49,999$ & $11.3 \%$ \\
\hline & $\$ 50,000$ to $\$ 74,999$ & $17.9 \%$ \\
\hline & $\$ 75,000$ to $\$ 99,999$ & $15.8 \%$ \\
\hline & $\$ 100,000$ to $\$ 149,999$ & $18.1 \%$ \\
\hline & $\$ 150,000$ to $\$ 199,999$ & $7.7 \%$ \\
\hline & $\$ 200,000$ or more & $6.7 \%$ \\
\hline
\end{tabular}

Page 10/26 


\section{Data Analysis Strategy}

Descriptive statistics as well as exploratory factor and reliability analyses were conducted using SPSS 27.0. Generalized linear mixed models were used to answer our research questions. Each model was fit with a logit link function and binomial distribution. Interest in each project concept was coded as yes (allocation of any points) or no (allocation of zero points). Due to the multiple sites involved in this study, interest in each project concept was modeled using random intercept mixed models. All predictive models were run in $\mathrm{R}$ with the glmmTMB package 1.0.2.1 (Brooks, Kristensen, van Benthem, Magnusson, et al., 2017).

Each model was tested in a series of steps: first, community characteristics were entered, followed by social position and COVID impact; additional steps added the independent variables for values, personality, and asset satisfaction and importance. The improvement of the models with the addition of variables after each step was assessed with the reduction in AIC. In summary, the specification for the models employed in the present study is shown in Table 2.

Table 2. Variables Included in Project Concept Interest Models 
Dependent Variables

Interest $(0 / 1)$ in each of:

- Renovating some downtown buildings as mixed-use facilities with retail shops and apartments

- Opening a community health center

- Deploying gigabit high-speed fiber broadband internet downtown

Stage 1: Community - Research Question 1

- Population (numeric, log(population))

- Population Density (numeric, people/square mile)

- Distance to the nearest major metro area (numeric, $\mathrm{km}$ )

Stage 2: Social Position - Research Question 2 (and COVID Controls)

- Age (numeric, with the value taken at the lower end of each categorical range)

- Gender (reference = male)

- Minority Race/Ethnicity (reference =White)

- Education (Reference = Less than college degree)

- COVID impact on community's health (numeric, 1-7 agreement rating)

- COVID impact on community's economy (numeric, 1-7 agreement rating)

Stage3: Predictors for Research Question 3

- Resultant Self-Transcendence, Self-Transcendence - Self Enhancement (numeric, difference between two 1-7 subscale mean agreement ratings)

- Resultant Conservation, Conservation - Openness to Change (numeric, difference between two 1-7 subscale mean agreement rating)

- Agreeableness (numeric, 1-7 subscale mean agreement rating)

- Openness (numeric, 1-7 subscale mean agreement rating)

Stage 4: Predictors for Research Questions 4

- Satisfaction with broad-based community services (numeric, 1-7 mean rating)

- Satisfaction with economic environment (numeric, 1-7 mean rating)

- Satisfaction with family-oriented community services (numeric, 1-7 mean rating)

- Satisfaction with communications services (numeric, 1-7 mean rating)

- Importance of broad-based community services (numeric, 1-7 mean rating)

- Importance of economic environment (numeric, 1-7 mean rating)

- Importance of family-oriented community services (numeric, 1-7 mean rating)

- Importance of communications services (numeric, 1-7 mean rating)

[1] Dynata.com

\section{Results}

Table 3 summarizes the hierarchal model results for the three community development project concepts, including fit statistics for each model as information is added to the hierarchy. The table includes the Akaike information criteria (AIC) for each model, the change in the $X^{2}$ statistic as information is added, and the significance of the change in model fit.

More specifically, Table 3 shows the change in model fit when the following stages of information are added to the models for each community development project concept: 1) a random intercept is included to control for variability across the sites in the study, 2) three location variables for each community, 3) social position and community perceptions of the impact of COVID on the community, 4) four variables for personal values and personality, and 5) eight asset satisfaction

Page $12 / 26$ 
and importance variables. The inclusion of the random intercept improved fit for all models. The sequential addition of location variables significantly improved fit for the model for the community health center $(p<0.009)$. (The improvement in fit for gigabit fiber was significant at $p=0.055$.) Fit was improved significantly after the addition of social position and community perceptions of the impact of COVID for all models; all significant at $p<0.001$. The addition of personal values and personality variables significantly improved the fit of the model for downtown renovation $(p<0.001)$, but did not improve the fit of the models for opening a community health center or adding gigabit fiber downtown. The fit of all three models was improved by the addition of information about perceptions about satisfaction and importance of community assets, all significant at $p \leq 0.001$.

Table 3

Hierarchical Modeling Summary

\begin{tabular}{|c|c|c|c|c|c|}
\hline \multicolumn{6}{|c|}{ Downtown Renovation for Mixed Use Facilities } \\
\hline & df & AIC & $\Delta \mathrm{X}^{2}$ & $\Delta \mathrm{X}^{2} \mathrm{df}$ & Sig. \\
\hline Intercept & 1 & 5228.6 & & & \\
\hline Random Intercept & 2 & 5109.3 & 121.3 & 1 & 0.000 \\
\hline Location & 5 & 5112.4 & 2.9 & 3 & 0.406 \\
\hline Social Position & 11 & 5096.3 & 28.1 & 6 & 0.000 \\
\hline Values \& Personality & 15 & 5044.4 & 60.0 & 4 & 0.000 \\
\hline Asset Satisfaction and Importance & 23 & 5033.8 & 26.6 & 8 & 0.001 \\
\hline \multicolumn{6}{|l|}{ Community Health Center } \\
\hline & df & AlC & $\Delta X^{2}$ & $\Delta \mathrm{X}^{2} \mathrm{df}$ & Sig. \\
\hline Intercept & 1 & 5695.0 & & & \\
\hline Random Intercept & 2 & 5523.6 & 173.4 & 1 & 0.000 \\
\hline Location & 5 & 5518.1 & 11.5 & 3 & 0.009 \\
\hline Social Position & 11 & 5487.5 & 42.6 & 6 & 0.000 \\
\hline Values \& Personality & 15 & 5493.0 & 2.5 & 4 & 0.644 \\
\hline Asset Satisfaction and Importance & 23 & 5424.9 & 84.2 & 8 & 0.000 \\
\hline \multicolumn{6}{|l|}{ Gigabit Fiber Broadband Downtown } \\
\hline & df & AlC & $\Delta \mathrm{X}^{2}$ & $\Delta \mathrm{X}^{2} \mathrm{df}$ & Sig. \\
\hline Intercept & 1 & 6569.5 & & & \\
\hline Random Intercept & 2 & 6430.4 & 141.1 & 1 & 0.000 \\
\hline Location & 5 & 6428.8 & 7.6 & 3 & 0.055 \\
\hline Social Position & 11 & 6381.2 & 59.7 & 6 & 0.000 \\
\hline Values \& Personality & 15 & 6384.8 & 4.3 & 4 & 0.365 \\
\hline Asset Satisfaction and Importance & 23 & 6294.9 & 105.9 & 8 & 0.000 \\
\hline
\end{tabular}

Tables 4a, 4b, and 4c show the detailed results for each community development project concept as perceived by communities, and include the adjusted odds ratio (AOR), standard error (SE), and the significance (Sig.) for all terms in 
each model. We focus our discussion on model effects (AOR) that are significant at 0.05 or less, and organize this discussion around our research questions. The presentation of these results will start with the results from the hierarchical modeling process across all three concepts followed by a presentation of the results for our research questions for each model taken in turn: question 1 (community characteristics), 2 (social position), 3 (personal values and personality types), and 4 (asset satisfaction and importance).

The discussion of these models focuses on the final, or full, model. Only one change in the structural results were observed as stages of information were added to the hierarchy. Specifically, for the community health center model, age dropped from significance in the final model, but earlier stages indicated that increased age predicted lower interest in this concept.

Downtown renovation for mixed use facilities. As shown in Table 4a, increasing age predicts a lower likelihood of interest in a downtown renovation for mixed use facilities $(A O R=0.994, p=0.020)$. A more agreeable personality predicts a higher likelihood of interest in a downtown renovation for mixed use facilities ( $A O R=1.098, p=0.033)$. Greater resultant selftranscendence predicts a lower likelihood of interest in a downtown renovation for mixed use facilities $(A O R=.860, p<$ 0.001). Higher satisfaction with available broadband and cellular/mobile predicts a higher likelihood of interest in a downtown renovation for mixed use facilities $(A O R=1.098, p=0.005)$.

Community health center. As shown in Table 4b, minority status predicts a higher likelihood of interest in a community health center $(A O R=1.303, p=0.002)$. Perceiving a greater health impact of COVID on one's community predicts a higher likelihood of interest in a community health center $(A O R=1.085, p=0.015)$. Additively, lower satisfaction with and greater perceived importance of available family-oriented community services predict a higher likelihood of interest in a community health center, respectively $(A O R=0.815, p<0.001)$ and $(A O R=1.190, p<0.001)$. Additively, higher satisfaction with and lower perceived importance of available broadband and cellular/mobile predict a higher likelihood of interest in a community health center $(A O R=1.105, p<0.001)$ and $(A O R=0.992, p=0.008)$. Greater perceived importance of broadbased community services predicts a higher likelihood of interest in a community health center $(A O R=1.161, p=0.001)$. Greater perceived importance of the economic environment predicts a lower likelihood of interest in a community health center $(\mathrm{AOR}=0.832, \mathrm{p}<0.001)$.

Adding gigabit fiber to a downtown area. As shown in Table 4c, increased distance from a major metro area predicts a lower likelihood of interest in adding gigabit fiber to a downtown area (AOR $=.999, p=0.034)$. Female community members are less likely than males to be interested in adding gigabit fiber to a downtown area $(A O R=0.786, p=0.001)$. Community members with at least an undergraduate degree are more likely than community members with less education to be interested in adding gigabit fiber to a downtown area $(A O R=1.420, p<0.001)$. Additively, lower satisfaction with and higher perceived importance of available broadband and cellular/mobile predict a higher likelihood of interest in adding gigabit fiber to a downtown area $(A O R=0.839, p<0.001)$ and $(A O R=1.213, p<0.001)$. Higher perceived importance of broad-based community services predict a lower likelihood of interest in adding gigabit fiber to a downtown area (AOR = $0.923, p=0.046$ ). 
Table 4

a. Downtown Renovation for Mixed Use Facilities Concept Interest Model Results (Fixed Effects from GLMM Logistic with $\mathrm{RI})$

\begin{tabular}{|c|c|c|c|c|c|c|c|c|c|c|c|c|}
\hline & \multicolumn{3}{|c|}{ Location } & \multicolumn{3}{|c|}{ + Identity } & \multicolumn{3}{|c|}{ + Values \& Personality } & \multicolumn{3}{|c|}{$\begin{array}{l}\text { + Asset Satisf. \& } \\
\text { Importance }\end{array}$} \\
\hline & AOR & SE & Sig. & AOR & SE & Sig. & AOR & SE & Sig. & AOR & SE & Sig. \\
\hline Intercept & 3.383 & 0.20 & 0.000 & 6.451 & 0.26 & 0.000 & 5.812 & 0.31 & 0.000 & 4.368 & 0.44 & 0.001 \\
\hline $\begin{array}{l}\text { Log } \\
\text { Population } \\
\text { (000) }\end{array}$ & 0.942 & 0.06 & 0.346 & 0.927 & 0.06 & 0.228 & 0.922 & 0.06 & 0.197 & 0.928 & 0.06 & 0.235 \\
\hline $\begin{array}{l}\text { Population } \\
\text { Density }\end{array}$ & 1.000 & 0.00 & 0.264 & 1.000 & 0.00 & 0.295 & 1.000 & 0.00 & 0.370 & 1.000 & 0.00 & 0.494 \\
\hline $\begin{array}{l}\text { Distance to } \\
\text { nearest Urban } \\
\text { Center }(\mathrm{km})\end{array}$ & 1.001 & 0.00 & 0.281 & 1.000 & 0.00 & 0.330 & 1.001 & 0.00 & 0.296 & 1.000 & 0.00 & 0.387 \\
\hline Age & & & & 0.989 & 0.00 & 0.000 & 0.994 & 0.00 & 0.019 & 0.994 & 0.00 & 0.020 \\
\hline Female & & & & 0.841 & 0.08 & 0.029 & 0.916 & 0.08 & 0.280 & 0.928 & 0.08 & 0.363 \\
\hline Minority & & & & 0.941 & 0.09 & 0.492 & 0.935 & 0.09 & 0.451 & 0.941 & 0.09 & 0.507 \\
\hline $\begin{array}{l}\text { Undergrad } \\
\text { degree or more }\end{array}$ & & & & 1.134 & 0.07 & 0.089 & 1.114 & 0.08 & 0.149 & 1.082 & 0.08 & 0.298 \\
\hline $\begin{array}{l}\text { COVID health } \\
\text { impact }\end{array}$ & & & & 1.047 & 0.04 & 0.197 & 1.031 & 0.04 & 0.388 & 1.037 & 0.04 & 0.317 \\
\hline $\begin{array}{l}\text { COVID } \\
\text { economic } \\
\text { impact }\end{array}$ & & & & 0.973 & 0.04 & 0.460 & 0.979 & 0.04 & 0.575 & 0.995 & 0.04 & 0.891 \\
\hline Agreeableness & & & & & & & 1.088 & 0.04 & 0.048 & 1.098 & 0.04 & 0.033 \\
\hline Openness & & & & & & & 0.991 & 0.04 & 0.827 & 0.993 & 0.04 & 0.880 \\
\hline $\begin{array}{l}\text { Self- } \\
\text { Transcendence } \\
\text { - Self- } \\
\text { Enhancement }\end{array}$ & & & & & & & 0.856 & 0.02 & 0.000 & 0.860 & 0.02 & 0.000 \\
\hline $\begin{array}{l}\text { Conservation - } \\
\text { Openness to } \\
\text { Change }\end{array}$ & & & & & & & 0.960 & 0.02 & 0.082 & 0.959 & 0.02 & 0.080 \\
\hline $\begin{array}{l}\text { Sat. with } \\
\text { broad-based } \\
\text { community } \\
\text { services }\end{array}$ & & & & & & & & & & 0.887 & 0.04 & 0.004 \\
\hline $\begin{array}{l}\text { Sat. with } \\
\text { economic } \\
\text { environment }\end{array}$ & & & & & & & & & & 1.062 & 0.04 & 0.107 \\
\hline $\begin{array}{l}\text { Sat. with } \\
\text { family-oriented } \\
\text { community } \\
\text { services }\end{array}$ & & & & & & & & & & 1.084 & 0.04 & 0.064 \\
\hline
\end{tabular}

Caption: AOR = Adjusted Odds Ratio, SE = Standard Error, Sig. = Significance. 


\begin{tabular}{|c|c|c|c|c|}
\hline \multirow[b]{2}{*}{$\begin{array}{l}\text { Sat. with } \\
\text { broadband } \\
\text { and } \\
\text { cellular/mobile }\end{array}$} & \multirow[t]{2}{*}{ + Values \& Personality } & \multicolumn{3}{|c|}{$\begin{array}{l}\text { + Asset Satisf. \& } \\
\text { Importance }\end{array}$} \\
\hline & & 1.075 & 0.03 & 0.005 \\
\hline $\begin{array}{l}\text { Imp. of broad- } \\
\text { based } \\
\text { community } \\
\text { services }\end{array}$ & & 1.049 & 0.05 & 0.302 \\
\hline $\begin{array}{l}\text { Imp. of } \\
\text { economic } \\
\text { environment }\end{array}$ & & 0.929 & 0.05 & 0.136 \\
\hline $\begin{array}{l}\text { Imp. of family- } \\
\text { oriented } \\
\text { community } \\
\text { services }\end{array}$ & & 1.027 & 0.05 & 0.577 \\
\hline $\begin{array}{l}\text { Imp. of } \\
\text { broadband } \\
\text { and } \\
\text { cellular/mobile }\end{array}$ & & 0.970 & 0.03 & 0.339 \\
\hline
\end{tabular}


Table 4

b. Community Health Center Concept Interest Model Results (Fixed Effects from GLMM Logistic with RI)

\begin{tabular}{|c|c|c|c|c|c|c|c|c|c|c|c|c|}
\hline & \multicolumn{3}{|c|}{ Location } & \multicolumn{3}{|c|}{ + Identity } & \multicolumn{3}{|c|}{ + Values \& Personality } & \multicolumn{3}{|c|}{$\begin{array}{l}\text { + Asset Satisf. \& } \\
\text { Importance }\end{array}$} \\
\hline & AOR & SE & Sig. & AOR & SE & Sig. & AOR & SE & Sig. & AOR & SE & Sig. \\
\hline Intercept & 1.877 & 0.17 & 0.000 & 1.968 & 0.24 & 0.004 & 2.055 & 0.29 & 0.013 & 2.145 & 0.41 & 0.064 \\
\hline $\begin{array}{l}\text { Log } \\
\text { Population } \\
(000)\end{array}$ & 1.118 & 0.06 & 0.055 & 1.085 & 0.06 & 0.160 & 1.085 & 0.06 & 0.158 & 1.069 & 0.06 & 0.252 \\
\hline $\begin{array}{l}\text { Population } \\
\text { Density }\end{array}$ & 1.000 & 0.00 & 0.834 & 1.000 & 0.00 & 0.888 & 1.000 & 0.00 & 0.884 & 1.000 & 0.00 & 0.923 \\
\hline $\begin{array}{l}\text { Distance to } \\
\text { nearest Urban } \\
\text { Center }(\mathrm{km})\end{array}$ & 1.000 & 0.00 & 0.925 & 1.000 & 0.00 & 0.829 & 1.000 & 0.00 & 0.834 & 1.000 & 0.00 & 0.563 \\
\hline Age & & & & 0.995 & 0.00 & 0.020 & 0.995 & 0.00 & 0.029 & 0.996 & 0.00 & 0.153 \\
\hline Female & & & & 1.044 & 0.07 & 0.560 & 1.042 & 0.08 & 0.588 & 1.025 & 0.08 & 0.746 \\
\hline Minority & & & & 1.403 & 0.09 & 0.000 & 1.392 & 0.09 & 0.000 & 1.303 & 0.09 & 0.002 \\
\hline $\begin{array}{l}\text { Undergrad } \\
\text { degree or more }\end{array}$ & & & & 1.026 & 0.07 & 0.718 & 1.031 & 0.07 & 0.668 & 1.041 & 0.07 & 0.572 \\
\hline $\begin{array}{l}\text { COVID health } \\
\text { impact }\end{array}$ & & & & 1.105 & 0.03 & 0.002 & 1.103 & 0.03 & 0.003 & 1.085 & 0.03 & 0.015 \\
\hline $\begin{array}{l}\text { COVID } \\
\text { economic } \\
\text { impact }\end{array}$ & & & & 0.986 & 0.04 & 0.683 & 0.988 & 0.04 & 0.740 & 0.992 & 0.04 & 0.823 \\
\hline Agreeableness & & & & & & & 0.968 & 0.04 & 0.420 & 0.960 & 0.04 & 0.332 \\
\hline Openness & & & & & & & 1.026 & 0.04 & 0.520 & 1.058 & 0.04 & 0.173 \\
\hline $\begin{array}{l}\text { Self- } \\
\text { Transcendence } \\
\text { - Self- } \\
\text { Enhancement }\end{array}$ & & & & & & & 0.973 & 0.02 & 0.213 & 0.974 & 0.02 & 0.230 \\
\hline $\begin{array}{l}\text { Conservation - } \\
\text { Openness to } \\
\text { Change }\end{array}$ & & & & & & & 1.003 & 0.02 & 0.895 & 1.005 & 0.02 & 0.815 \\
\hline $\begin{array}{l}\text { Sat. with } \\
\text { broad-based } \\
\text { community } \\
\text { services }\end{array}$ & & & & & & & & & & 1.062 & 0.04 & 0.122 \\
\hline $\begin{array}{l}\text { Sat. with } \\
\text { economic } \\
\text { environment }\end{array}$ & & & & & & & & & & 1.001 & 0.04 & 0.967 \\
\hline $\begin{array}{l}\text { Sat. with } \\
\text { family-oriented } \\
\text { community } \\
\text { services }\end{array}$ & & & & & & & & & & 0.815 & 0.04 & 0.000 \\
\hline
\end{tabular}

Caption: AOR = Adjusted Odds Ratio, SE = Standard Error, Sig. = Significance. 


\begin{tabular}{|lccc|}
\hline \multicolumn{1}{c}{ Location } & + Identity & +Values \& Personality & \multicolumn{2}{c|}{$\begin{array}{l}\text { + Asset Satisf. \& } \\
\text { Importance }\end{array}$} \\
\hline $\begin{array}{l}\text { Sat. with } \\
\text { broadband } \\
\text { and } \\
\text { cellular/mobile }\end{array}$ & 1.105 & 0.02 & 0.000 \\
\hline $\begin{array}{l}\text { Imp. of broad- } \\
\text { based } \\
\text { community } \\
\text { services }\end{array}$ & & & \\
\hline $\begin{array}{l}\text { Imp. of } \\
\text { economic } \\
\text { environment }\end{array}$ & 1.161 & 0.04 & 0.001 \\
\hline $\begin{array}{l}\text { Imp. of family- } \\
\text { oriented } \\
\text { community } \\
\text { services }\end{array}$ & & & \\
\hline $\begin{array}{l}\text { Imp. of } \\
\text { broadband } \\
\text { and } \\
\text { cellular/mobile }\end{array}$ & 0.832 & 0.05 & 0.000 \\
\hline Caption: AOR = Adjusted Odds Ratio, SE = Standard Error, Sig. = Significance. & 1.190 & 0.05 & 0.000 \\
\hline
\end{tabular}


Table 4

c. Gigabit Fiber Downtown Concept Interest Model Results (Fixed Effects from GLMM Logistic with RI)

\begin{tabular}{|c|c|c|c|c|c|c|c|c|c|c|c|c|}
\hline & \multicolumn{3}{|c|}{ Location } & \multicolumn{3}{|c|}{ + Identity } & \multicolumn{3}{|c|}{ + Values \& Personality } & \multicolumn{3}{|c|}{$\begin{array}{l}\text { + Asset Satisf. \& } \\
\text { Importance }\end{array}$} \\
\hline & AOR & SE & Sig. & AOR & SE & Sig. & AOR & SE & Sig. & AOR & SE & Sig. \\
\hline Intercept & 1.968 & 0.16 & 0.000 & 1.696 & 0.22 & 0.015 & 1.839 & 0.26 & 0.021 & 1.711 & 0.37 & 0.146 \\
\hline $\begin{array}{l}\text { Log } \\
\text { Population } \\
\text { (000) }\end{array}$ & 0.979 & 0.05 & 0.695 & 0.971 & 0.05 & 0.579 & 0.973 & 0.05 & 0.599 & 0.985 & 0.05 & 0.769 \\
\hline $\begin{array}{l}\text { Population } \\
\text { Density }\end{array}$ & 1.000 & 0.00 & 0.431 & 1.000 & 0.00 & 0.370 & 1.000 & 0.00 & 0.375 & 1.000 & 0.00 & 0.148 \\
\hline $\begin{array}{l}\text { Distance to } \\
\text { nearest Urban } \\
\text { Center (km) }\end{array}$ & 0.999 & 0.00 & 0.008 & 0.999 & 0.00 & 0.006 & 0.999 & 0.00 & 0.007 & 0.999 & 0.00 & 0.034 \\
\hline Age & & & & 1.004 & 0.00 & 0.058 & 1.005 & 0.00 & 0.034 & 1.003 & 0.00 & 0.201 \\
\hline Female & & & & 0.805 & 0.07 & 0.001 & 0.805 & 0.07 & 0.002 & 0.786 & 0.07 & 0.001 \\
\hline Minority & & & & 0.964 & 0.08 & 0.634 & 0.968 & 0.08 & 0.676 & 0.954 & 0.08 & 0.547 \\
\hline $\begin{array}{l}\text { Undergrad } \\
\text { degree or more }\end{array}$ & & & & 1.422 & 0.06 & 0.000 & 1.406 & 0.06 & 0.000 & 1.420 & 0.07 & 0.000 \\
\hline $\begin{array}{l}\text { COVID health } \\
\text { impact }\end{array}$ & & & & 1.072 & 0.03 & 0.022 & 1.070 & 0.03 & 0.026 & 1.062 & 0.03 & 0.051 \\
\hline $\begin{array}{l}\text { COVID } \\
\text { economic } \\
\text { impact }\end{array}$ & & & & 0.930 & 0.03 & 0.024 & 0.928 & 0.03 & 0.021 & 0.918 & 0.03 & 0.009 \\
\hline Agreeableness & & & & & & & 0.960 & 0.04 & 0.260 & 0.947 & 0.04 & 0.154 \\
\hline Openness & & & & & & & 1.009 & 0.04 & 0.800 & 1.012 & 0.04 & 0.749 \\
\hline $\begin{array}{l}\text { Self- } \\
\text { Transcendence } \\
\text { - Self- } \\
\text { Enhancement }\end{array}$ & & & & & & & 1.000 & 0.02 & 0.997 & 0.997 & 0.02 & 0.878 \\
\hline $\begin{array}{l}\text { Conservation - } \\
\text { Openness to } \\
\text { Change }\end{array}$ & & & & & & & 0.963 & 0.02 & 0.065 & 0.964 & 0.02 & 0.078 \\
\hline $\begin{array}{l}\text { Sat. with } \\
\text { broad-based } \\
\text { community } \\
\text { services }\end{array}$ & & & & & & & & & & 1.036 & 0.04 & 0.318 \\
\hline $\begin{array}{l}\text { Sat. with } \\
\text { economic } \\
\text { environment }\end{array}$ & & & & & & & & & & 0.992 & 0.03 & 0.793 \\
\hline $\begin{array}{l}\text { Sat. with } \\
\text { family-oriented } \\
\text { community } \\
\text { services }\end{array}$ & & & & & & & & & & 0.989 & 0.04 & 0.762 \\
\hline
\end{tabular}

Caption: AOR = Adjusted Odds Ratio, SE = Standard Error, Sig. = Significance. 


\begin{tabular}{|c|c|c|c|c|c|}
\hline \multirow[b]{2}{*}{$\begin{array}{l}\text { Sat. with } \\
\text { broadband } \\
\text { and } \\
\text { cellular/mobile }\end{array}$} & \multirow[t]{2}{*}{ + Identity } & \multirow[t]{2}{*}{ + Values \& Personality } & \multicolumn{3}{|c|}{$\begin{array}{l}\text { + Asset Satisf. \& } \\
\text { Importance }\end{array}$} \\
\hline & & & 0.839 & 0.02 & 0.000 \\
\hline $\begin{array}{l}\text { Imp. of broad- } \\
\text { based } \\
\text { community } \\
\text { services }\end{array}$ & & & 0.923 & 0.04 & 0.046 \\
\hline $\begin{array}{l}\text { Imp. of } \\
\text { economic } \\
\text { environment }\end{array}$ & & & 1.012 & 0.04 & 0.783 \\
\hline $\begin{array}{l}\text { Imp. of family- } \\
\text { oriented } \\
\text { community } \\
\text { services }\end{array}$ & & & 1.003 & 0.04 & 0.941 \\
\hline $\begin{array}{l}\text { Imp. of } \\
\text { broadband } \\
\text { and } \\
\text { cellular/mobile }\end{array}$ & & & 1.213 & 0.03 & 0.000 \\
\hline
\end{tabular}

\section{Discussion}

The present study illustrates that interest in various community development project concepts is differentially and variously correlated with many factors, including the identities of community members, their personalities, and personal values, as well as their levels of satisfaction with and the importance of the assets that are available in their community. However, the patterns seen in the connections among these factors, and interest in community development projects, differ little along degrees of urbanity and rurality as measured in the present study, though they do hint at how relationships among communities may effect these processes.

Agreeableness is positively associated with interest in a downtown renovation for mixed-use facilities, while resultant selftranscendence is negatively associated with interest in the same community development concept. Neither is associated with interest in a community health center or adding Gigabit fiber. Satisfaction with broadband and cellular/mobile services is connected to interest in a downtown renovation for mixed-use facilities.

Interest in a community health center is connected to minority status. However, interest is also connected to satisfaction with and perception of the importance of several community assets. In particular, lower levels of satisfaction and higher perceptions of importance for family-oriented community services are connected to interest in a community health center. Interestingly, higher levels of satisfaction and lower perceptions of importance for broadband and cellular/mobile are connected to interest in a community health center.

These results highlight the necessity of including local perspectives in sustainably developing a community, in agreement with the SLED model. Additionally, these results illustrate that decision-making about community development is connected to both emotional perspectives held by community members and their rational assessment of the performance of assets in their community. Further, the role of these emotional and rational decision drivers varies by the context of the decision being considered. 
Findings presented here reinforce the complex understanding of the interconnectedness among community, personality, and satisfaction/importance variables in community economic development presented in the SLED and ABCD

frameworks. Both approaches deal with individuals, relationships, and organizations to optimize community development decision-making. This paper has shown that personality traits, too, affect the relationships people form, their motivations for engaging with others, and the types of activities in which they engage (community development being one such activity).

While community-level characteristics had a limited impact on development project preferences - distance from an urban center decreasing support for the broadband intervention - their qualified significance and inclusion in this study went beyond the frameworks of $A B C D$ and SLED speaking to the relationship communities have to each other. Part of $A B C D$ is the creation of communities through interaction. Knowing that a community is close to an urban center where there are generally centralized assets, resources and services could tend to make one feel just as connected to that center as their home community, and thus not see their community as lacking. Population size and density also increases individuals' ability to interact with others, therefore making different types of development activity possible, increasing the assets in play. If communities are far from urban centers, or have low populations that are spread apart from one another, then interaction among community members is harder and there will be more gaps in agreement on what improvements in which to invest. The models and data presented here only partially confirm this intuition, and further research on community distance from major urban metropolitan areas, community identity, and gaps in satisfaction and importance should be further developed.

\section{Conclusions}

This analysis clarifies the complex role of community characteristics, the personal values and personality types of members of those communities, and the assessment by community members of their satisfaction with and the importance that they perceive for various assets available in the community. All of these factors have the potential to influence interest in different community development concepts, but they also do so differently across concepts. These nuanced results reinforce the benefits of incorporating local community perspectives in community development planning and approaching the development process as purposefully addressing a system of subsystems (Nel 2018). Indeed, different community development concepts fill the needs of different community segments because they enhance or expand different subsystems. The findings presented here also locate opportunities to engage in further practical interventions within the community development process. Our findings specifically highlight areas where human-centered, participatory processes can be brought in to guide further interactions between experts and community members to 1) identify groups in the community to bring into the process who may be most affected by the choice of one intervention over another, as well as 2) target areas where further community discussion and deliberation is necessary around which community dialogues (round tables, town halls, workshops, etc.) could be facilitated.

The first type of practical intervention seeks to identify who in the community is most interested in a given type of community development project in order to get both an idea of who the project is serving as well as who should be targeted for outreach and brought further into the development process. The findings related to the Community Health Center project intervention showed that minority-status was an outsized predictor for gauging levels of support for this intervention. In this instance, minorities supported establishing a Community Health Center more than white community members, which makes sense given the large disparities that exist in healthcare provision along racial lines. Minorities have historically been left out of community development decision-making and have been the most under-served by development interventions as a result, making the benefits of this development project to minority community members especially impactful. These concerns over inclusion and exclusion find themselves reappearing along different lines across community development processes, which should push researchers and practitioners to step back and ask about who is being represented in the decision-making process, whether they are representative of the community as a whole, and

Page $21 / 26$ 
whether the right voices and perspectives have been engaged. The success of a community choosing such a project relies on targeting and engaging various groups of community members in the decision-making process through outreach.

The second type of intervention seeks to identify and target specific domains of intervention where community preferences and priorities are still inchoate and could benefit from further discussion and deliberation. The findings related to the broadband project intervention above reveal that while experts have repeatedly shown that rural broadband is extremely important for both community wellbeing and economic growth, support for broadband interventions declined among our respondents the farther they lived from an urban center. This may be a situation where local perceptions are a barrier to implementing community development initiatives that are known to produce positive and outsized benefits in just such a community. In such a situation, a round table could be planned where experts and members of other similar communities that implemented broadband projects could share how their communities benefitted from broadband and share the struggles they faced in implementing their projects. The goal of facilitating such a community dialogue would be to make community members aware of the unknowns of a given project while also encouraging discussion and collaboration across communities to this end, forming relationships that could support and guide the community development process moving forward.

This analysis of community development priorities across geographies in a large U.S. state reveals more commonalities than differences between urban and rural residents. Surprisingly, preferences among economic and quality of life development choices did not break cleanly into an urban-rural binary but were dependent on a far more complex set of identities. Economic development professionals would be well advised to acknowledge this complexity in their communities when weighing the choices available to them, for the well-being of their whole community.

\section{Declarations}

\section{Acknowledgements}

This research was generously supported by the Carl B. \& Florence E. King Foundation and the Cynthia and George Mitchell Foundation.

\section{Conflict of interest/Ethical Statement}

The authors have no relevant financial or non-financial interests to disclose.

\section{References}

Ahmad, W., Kim, W. G., Anwer, Z., \& Zhuang, W. (2020). Schwartz personal values, theory of planned behavior and environmental consciousness: How tourists' visiting intentions towards eco-friendly destinations are shaped? Journal of Business Research, 110, 228-236. https://doi.org/10.1016/j.jbusres.2020.01.040

Adashi, E. Y., Geiger, H. J., \& Fine, M. D. (2010). Health Care Reform and Primary Care-The Growing Importance of the Community Health Center. New England Journal of Medicine, 362(22), 20472050. https://doi.org/10.1056/NEJMp1003729

Ashraf, M. S., Hou, F., Kim, W. G., Ahmad, W., \& Ashraf, R. U. (2020). Modeling tourists' visiting intentions toward ecofriendly destinations: Implications for sustainable tourism operators. Business Strategy and the Environment, 29(1), 5471. https://doi.org/10.1002/bse.2350

Baldassare, M., \& Protash, W. (1982). Growth Controls, Population Growth, and Community

Satisfaction. American Sociological Review, 47(3), 339-346. https://doi.org/10.2307/2094990

Page 22/26 
Bartik, T. J. (2018). Who benefits from economic development incentives? How incentive effects on local incomes and the income distribution vary with different assumptions about incentive policy and the local economy. https://doi.org/10.17848/tr18-034

Brooks, M. E., Kristensen, K., van Benthem, K. J., Magnusson, A., Berg, C. W., Nielsen, A., Skaug, H. J., Maechler, M., Bolker, B.M. (2017). glmmTMB balances speed and flexibility among packages for zero-inflated generalized linear mixed modeling. The $R$ Journal, 9(2), 378- 400.

Brown, D., \& Kandel, W. (2006). Rural America through a demographic lens. In W. Kandel \& D. Brown (Eds.), Population Change and Rural Society (pp. 3-13). Springer.

Chang, A., Hsieh, S. H., \& Lin, F. (2013). Personality Traits That Lead Members of Online Brand Communities to Participate in Information Sending and Receiving. International Journal of Electronic Commerce, 17(3), 37-62.

Christensen, A. P., Cotter, K. N., \& Silvia, P. J. (2019). Reopening Openness to Experience: A Network Analysis of Four Openness to Experience Inventories. Journal of Personality Assessment, 101(6), 574-588.

https://doi.org/10.1080/00223891.2018.1467428

CNN, May 17, 2020. America's surprising breeding ground for inequality: The internet. https://www.cnn.com/2020/05/17/economy/internet-access-universal-wifi/index.html. Accessed 5/11/2021. Cobb-Clark, D., \& Schurer, S. (2011). The Stability of Big-Five Personality Traits. 14.

Cuthbertson, C. A., Albrecht, D. E., \& Loveridge, S. (2017). Community Development Rural versus urban perspectives on behavioral health issues and priorities. https://doi.org/10.1080/15575330.2017.1344718

Deller, S. C., Tsai, T. H., Marcouiller, D. W., \& English, D. B. K. (2001). The Role of Amenities and Quality of Life In Rural Economic Growth. American Journal of Agricultural Economics, 83(2), 352-365. https://doi.org/10.1111/00029092.00161

Deller, S. C., \& Conroy, T. (2016). Business survival rates across the urban-rural divide. 48(1), 6785. https://doi.org/10.1080/15575330.2016.1246459

Domina, T. (2006). Brain Drain and Brain Gain: Rising Educational Segregation in the United States, 1940-2000. City \& Community, 5(4), 387-407.

Donnenwerth, G. V, Guy, R. F., \& Norvell, M. J. (1978). Life Satisfaction among Older Persons: Rural-Urban and Racial Comparisons. Social Science Quarterly, 59(3), 578-583. https://www.jstor.org/stable/42860387

Fried, M. (1982). Residential Attachment: Sources of Residential and Community Satisfaction. Journal of Social Issues, 38(3), 107-119. https://doi.org/10.1111/j.1540-4560.1982.tb01773.x

Fried, M. (1984). The Structure and Significance of Community Satisfaction. Population and Environment, 7(2), 6186. https://www.jstor.org/stable/27503018

Füller, J., Matzler, K., \& Hoppe, M. (2008). Brand Community Members as a Source of Innovation. Journal of Product Innovation Management, 25(6), 608-619. https://doi.org/10.1111/j.1540-5885.2008.00325.x

Garretsen, H., Stoker, J., Soudis, D., Martin, R., \& Rentfrom, J. (2019). The Relevance of Personality Traits for Urban Economic Growth: Making Space for Psychological Factors. Journal of Economic Geography, 19(3), 541-565. 
Geiger, H. J. (2002). Community-Oriented Primary Care: A Path to Community Development. American Journal of Public Health, 92(11), 1713-1716. https://doi.org/10.2105/AJPH.92.11.1713

Gibson, H., Zurcher, M., \& Wisemiller, T. (2020). Beyond the façade: layering downtown spillover investment. Community Development. https://doi.org/10.1080/15575330.2020.1837195

Gimpel, J. G., Lovin, N., Moy, B., \& Reeves, A. (2020). The Urban-Rural Gulf in American Political Behavior. Political Behavior, 42(4), 1343-1368. https://doi.org/10.1007/s11109-020-09601-w

Green, G. P. (2017). Place-Based Approaches to Poverty Alleviation : Institutional Innovation and Asset-Based Community Development. In The Routledge Handbook of Community Development.

Hamilton, L. (2006). Rural voting in the 2004 election. Carsey Fact Sheet. No. 2.

http://www.carseyinstitute.unh.edu/publications/FS_ruralvote_06.pdf

Hanna, T. and Mitchell, C. May 2020. United States: Communities providing affordable, fast broadband Internet. Chapter 9 of The Future is Public: Towards Democratic Ownership of Public Services. https://www.tni.org/files/publicationdownloads/futureispublic_online_def.pdf. Accessed 5/11/2021/

Hannscott, L. (2016). Individual and contextual socioeconomic status and community satisfaction. Urban Studies, 53(8), 1727-1744. https://www.jstor.org/stable/26151144

Jeffres, L. W., Bracken, C. C., Jian, G., \& Casey, M. F. (2009). The impact of third places on community quality of life. Applied Research in Quality of Life, 4(4), 333.

John, O. P., Donahue, E. M., \& Kentle, R. L. (1991). Big Five Inventory. https://doi.org/10.1037/t07550-000

Keh, H. T., and Sun, J. (2008, March 1). The complexities of perceived risk in cross-cultural services marketing. Journal of International Marketing, Vol. 16, pp. 120-146. https://doi.org/10.1509/jimk.16.1.120

Kellogg Foundation. (2002). Perceptions of Rural America.

Kilkenny, M. (2010). Urban/Regional Economics and Rural Development. Journal of Regional Science, 50(1), 449-470.

Lichter, D. T., \& Brown, D. L. (2011). Rural America in an Urban Society: Changing Spatial and Social Boundaries. Annual Review of Sociology, 37, 565-592. https://www.jstor.org/stable/41288622

Litchfield, K., \& Javernick-Will, A. (2015). “I Am an Engineer AND”: A Mixed Methods Study of Socially Engaged Engineers. Journal of Engineering Education, 104(4), 393-416. https://doi.org/10.1002/jee.20102

Logan JR. (1996). Rural America as a symbol of American values. Rural Development Perspectives, 12(1), 19-21.

McGregor, J. A., Camfield, L., \& Woodcock, A. (2009). Needs, wants and goals: Wellbeing, quality of life and public policy. Applied Research in Quality of Life, 4(2), 135-154.

National Academies of Sciences and Medicine, E. (2016). Rationalizing Rural Area Classifications for the Economic Research Service: A Workshop Summary (G. S. Wunderlich, ed.). https://doi.org/10.17226/21843

$\mathrm{Nel}, \mathrm{H}$. (2018). A comparison between the asset-oriented and needs-based community development approaches in terms of systems changes. Practice, 30(1), 33-52. https://doi.org/10.1080/09503153.2017.1360474 
Newby, L. (1999). Sustainable local economic development: A new agenda for action? Local Environment, 4(1). https://doi.org/10.1080/13549839908725582

Nga, J. K. H., \& Shamuganathan, G. (2010). The Influence of Personality Traits and Demographic Factors on Social Entrepreneurship Start Up Intentions. Journal of Business Ethics, 95(2), 259-282.

Park, R. E., Burgess, E. W., \& McKenzie, R. D. (1926). The City. University of Chicago Press.

Parker, K., Horowitz, J.M., Brown, A., Fry, R., Cohn, D., and Igielnik, R. (2018). Report: What Unites and Divides Urban, Suburban and Rural Communities.

Pew Research Center. https://www.pewresearch.org/social-trends/2018/05/22/demographic-and-economic-trends-inurban-suburban-and-rural-communities/

Pendola, R., \& Gen, S. (2008). Does "main street” promote sense of community?: A comparison of San Francisco neighborhoods. Environment and Behavior, 4O(4), 545-574. https://doi.org/10.1177/0013916507301399

Pew Research Center, April 7, 2021. Internet/Broadband Fact Sheet. https://www.pewresearch.org/internet/factsheet/internet-broadband/. Accessed 5/11/2021.

Powe, N. A. (2020). Redesigning town centre planning: from master planning revival to enabling self-reorientation. Planning Theory and Practice, 21(2), 236-253. https://doi.org/10.1080/14649357.2020.1749719

Probst, J. C., Laditka, J. N., \& Laditka, S. B. (2009). Association between community health center and rural health clinic presence and county-level hospitalization rates for ambulatory care sensitive conditions: An analysis across eight US states. BMC Health Services Research, 9(1), 134. https://doi.org/10.1186/1472-6963-9-134

Rogers, S. H., Halstead, J. M., Gardner, K. H., \& Carlson, C. H. (2011). Examining walkability and social capital as indicators of quality of life at the municipal and neighborhood scales. Applied Research in Quality of Life, 6(2), 201-213.

Samuels, M. E., Xirasagar, S., Elder, K. T., \& Probst, J. C. (2008). Enhancing the Care Continuum in Rural Areas: Survey of Community Health Center-Rural Hospital Collaborations. The Journal of Rural Health, 24(1), 24-

31. https://doi.org/10.1111/j.1748-0361.2008.00133.x

Schmitt, D. P., Allik, J., McCrae, R. R., \& Benet-Martínez, V. (2007). The Geographic Distribution of Big Five Personality Traits: Patterns and Profiles of Human Self-Description Across 56 Nations. Journal of Cross-Cultural Psychology, 38(2), $173-212$. https://doi.org/10.1177/0022022106297299

Schwartz, S. H. (2012). An Overview of the Schwartz Theory of Basic Values. Online Readings in Psychology and Culture, 2(1). https://doi.org/10.9707/2307-0919.1116

Schwartz, S. H., Cieciuch, J., Vecchione, M., Davidov, E., Fischer, R., Beierlein, C., Ramos, A., Verkasalo, M., Lönnqvist, J. E., Demirutku, K., Dirilen-Gumus, O., \& Konty, M. (2012). Refining the theory of basic individual values. Journal of Personality and Social Psychology, 103(4), 663-688. https://doi.org/10.1037/a0029393

Soldz, S., \& Vaillant, G. E. (1999). The Big Five Personality Traits and the Life Course: A 45-Year Longitudinal Study. Journal of Research in Personality, 33(2), 208-232. https://doi.org/10.1006/jrpe.1999.2243

Simmel, G. (1950). "The Metropolis and Mental Life." In K. Wolff (Ed.), The Sociology of Georg Simmel (pp. 409-424). Free Press. 
Steenkamp, J.-B. E. M., ter Hofstede, F., \& Wedel, M. (1999). A Cross-National Investigation into the Individual and National Cultural Antecedents of Consumer Innovativeness. Journal of Marketing, 63(2), 55-

69. https://doi.org/10.1177/002224299906300204

Stinner, W. F., \& van Loon, M. (1992). Community Size Preference Status, Community Satisfaction and Migration Intentions. Population and Environment, 14(2), 177-195. https://www.jstor.org/stable/27503278

Theodori, G. L. (2001). Examining the Effects of Community Satisfaction and Attachment on Individual Well-Being. Rural Sociology, 66(4), 618-628. https://doi.org/10.1111/j.1549-0831.2001.tb00087.x

Vaughan, R., Pollard, R., \& Dyer, B. (1984). The wealth of states: Policies for a dynamic economy.

Weber, B., Jensen, L., Miller, K., Mosley, J., \& Fisher, M. (2005). A critical review of rural poverty literature: Is there truly a rural effect? International Regional Science Review, 28, 381-414.

The White House. March 31, 2021. Fact Sheet: The American Jobs Plan. https://www.whitehouse.gov/briefingroom/statements-releases/2021/03/31/fact-sheet-the-american-jobs-plan/. Accessed 5/11/2021.

Wilkening, E.A. (1982). Subjective indicators and the quality of life. In R. M. Hauser, D. Mechanic, A. O. Haller, \& J. S. Hauser (Eds.), Social structure and behavior (pp. 429-442). Academic Press.

Wirth, L. (1938). Urbanism as a Way of Life. American Journal of Sociology, 44(1), 1-24. 